\title{
Archaeological Ethics
}

Moshe Dayan, celebrated by many Israelis as one of the country's greatest military heroes and political leaders, is also remembered for his great passion for antiquities. In a recent biography, he is featured as a learned explorer of archaeological sites and as someone who saved antiquities from destruction. ${ }^{1}$ His daughter, Yael, describes her father's interest in archaeology and the collection featured in his home and garden: "My father resumed his ardent interest in archaeology, and whenever he could, he went digging or sat in the garden putting shards together. His collection grew, and the garden acquired a special near-magic when among the shrubs and flowers he placed Corinthian pillars and ancient millstones. The delight he took in his discoveries was still childlike and appealing, totally free of materialistic considerations."

In contrast to this romanticized depiction of Dayan's relationship with antiquities, most evaluations of his publicly known interest in ancient artifacts are rather harsh, accusing him of robbing and trading antiquities; of abusing his status by using army personnel and equipment to satisfy his greed and private pleasures; and of repeatedly denying his ethical and legal transgressions. ${ }^{3}$ Most of Dayan's collecting and looting activity - and the lack of legal sanction-would be considered unthinkable today. ${ }^{4}$ The academic discourse on archaeological ethics has evolved since his lifetime, and the laws regulating the excavation, trading, and handling of ancient burials are no longer the same. Some of Dayan's rather compulsive habits, however, have left their mark on Jerusalem's current antiquities scene and thus invite a critical analysis of ethical norms as they evolved over the last four decades. Some customs and rulings have clearly changed or developed; other traits have persisted. 
How do we best create a baseline for moral principles in the field of archaeology? Numerous ethical codes and standards have been formulated by different societies worldwide. Differences rarely concern the nature of the proclaimed principles, but rather the emphasis on certain values, which depend on two things: first, the specific experiences, circumstances, and concerns of the groups served by the organization, and second, the cultural and political framework in which the archaeological work is being conducted. Despite the fact that most ethical standards in the profession have universal value, some regulations pertain only to specific geographical and national contexts. Certain recommendations or rules, widely respected by professionals in other regions, can be of limited concern or of no relevance at all to the case of Jerusalem. A further singularity in the city is that archaeological practice-in spite of UNESCO's presence as representative of the international community-relies almost exclusively on Israeli legislation, which, for the most part, ignores and bypasses international rulings.

To better appreciate the development of archaeological norms in Jerusalem, it is useful to consider how the concern for ethical questions in the field emerged and evolved elsewhere. The academic interest in archaeological ethics first established itself in North America and Western Europe in the 1960s and 1970s, which resulted in the formulation of several codes of ethics. ${ }^{5}$ The discourse, largely theoretical in the beginning, was influenced by a new archaeology movement that began in the late 1950s, when researchers started to shift their attention away from the study of artifacts to the study of human behavior. ${ }^{6}$ Another factor was the establishment of public archaeology (also known as community archaeology, which is the dissemination of academic scholarship among the larger public) in the United States, following federal legislation. ${ }^{7}$ A more direct incentive to formulate and implement ethical standards came in 1970, through a UNESCO ratification to protect world culture. $^{8}$

In Israel, the Association of Archaeologists in Israel (AAI), founded in 1984, established the first local ethics committee. Their initiatives, however, were of relatively short duration and of minor impact on the archaeological community. ${ }^{9} \mathrm{~A}$ code, written between 1990 and 1992, included nine guidelines focusing primarily on the standards of fieldwork and publication, on professional relationships, and on the antiquities trade. ${ }^{10}$ Some of the issues addressed in the code had already been formulated in the much more authoritative 1978 Antiquities Law, incorporating rules for both excavation and publication. Though the intent of the ethics committee was to give "practical and ethical guidelines" to all archaeologists in Israel, their efforts never received much attention. ${ }^{11}$ One reason was that the initiatives of the AAI overlapped with the creation and fast expansion of the IAA, which, soon after its establishment in 1990, took on a leadership role in the profession and overshadowed the activities and academic profile of the AAI. ${ }^{12}$ In addition, some important issues were not addressed in the ethics committee's code, such as the 
rights of local communities over sites and finds and over the reburial of human remains. Thus, the code neglected numerous social, religious, and political dimensions that impact the divides among Jewish Israelis, as well as the rifts between Jews and Palestinians. ${ }^{13}$

Archaeological ethics encompass, indeed, an extremely wide spectrum of issues pertaining to how the profession is practiced, to the role of sites and artifacts, and also to the people whose heritage is being investigated. Central to this rapidly growing field are several widely circulated questions, such as: Who owns the past? Whose heritage is being investigated? Which remains should be documented, preserved, and presented to the public? How does the past tie into the present? And how do political agendas and identity formation interact with archaeological practice? All these questions are relevant to the discussion of archaeological ethics in Jerusalem. Some, however, are also being addressed either explicitly or implicitly in other chapters of this study. This chapter focuses on three select topics that have a particularly timely relevance and show how ethical standards have been significantly compromised in the past two decades. The first relates to professional standards; the second to acquisition, collection, and display policies; and the third to the excavation and desecration of tombs.

\section{PROFESSIONAL STANDARDS}

Excavation, documentation, and interpretation procedures have undergone important changes since the beginning of archaeological excavation in Jerusalem, regionally, and worldwide. What was considered acceptable practice in the nineteenth or mid-twentieth century is different from what conforms to ethical standards in the twenty-first century. By and large, the archaeological community in Jerusalem has fairly consistently held to the highest professional standards. Even prior to the academic discourse on the ethical necessity of employing the most advanced scientific methods in the field, excavations conducted in Jerusalem conformed to standard international practice. Since 1967, however-and in more drastic ways since the mid-1990s-the ideological pursuit of establishing a continued Jewish presence in East Jerusalem has compromised this positive trend.

Since the beginning of Israeli rule, first under the IDAM and with increased rigor under the IAA, professional standards have been formulated, regulated, and even sanctioned by a number of explicit rules and laws. These have insured that all excavations are conducted by professional archaeologists, for the most part with an academic degree in archaeology and extensive field experience. Fieldwork can be carried out only with proper survey and excavation licenses. The most meticulous recording and documentation procedures have to be followed. Preliminary and final excavation reports have to be published in a regular and timely manner. Specialized teams cooperate in the most effective ways. Regular training sessions, 
workshops, and conferences ensure the knowledge and use of up-to-date excavation, publication, and research methods, and they facilitate a continued education. The preservation of finds and their public display and dissemination among the general public are considered high priorities. All those rules have been and still are strictly governed and implemented by the IAA.

Despite of these high professional standards, however, one obvious shortcoming of Israeli archaeology, also discussed in other parts of this study, is the preferential treatment of remains from the First and Second Temple periods, highlighting finds of relevance to the city's Jewish narrative, to the neglect of other cultures and periods. This clear deviation from ethical standards has been the subject of much criticism, and it is seen in most public displays of excavations conducted since 1967 . One thing that has changed since the mid-199os is that medieval and Islamic layers are no longer bulldozed. Instead, most IAA excavations now meticulously record and dutifully document the remains that span the entire spectrum of pre-170o periods, as stipulated by the AL. Some select projects even document and record more recent layers, including the late Ottoman period, the time of the British Mandate, and, in some cases, the destruction layers associated with the 1948 and 1967 wars. At least in that respect, they are following the standard protocol of salvage excavations. ${ }^{14}$ Today, it is only the public presentation and dissemination of information that continues to focus on the Jewish narrative. Thus, professional archaeological practices-increasingly conscientious in other ways-do not really stand in the way of the continued commitment to the Zionist ideology, which emphasizes the continuity of a Jewish presence since antiquity and the entitlement of return to the Jewish homeland.

One issue discussed in the AAI codes of ethics but not commonly addressed in codes from other countries or continents concerns professional relations between colleagues, as well as between mentors and students. In Israel, there is an expectation that university archaeology students will assist their teachers and advisors in fieldwork and research projects-often for years and even decades-without receiving proper credit. This appears to be a tradition that will be difficult to break. For instance, the Hebrew University Institute of Archaeology's almost exclusive hiring of internally trained students is likely linked to this trend and is, without doubt, problematic. ${ }^{15}$ An equally neglected problem is the uneven professional distribution of Ashkenazi, Sephardic, and female employees, as well as the predomination of Jewish versus Palestinian Israeli archaeologists in higher-ranked positions, not only in academia, but also in most relevant governmental and nongovernmental institutions. ${ }^{16}$

In addition to this professional and academic exploitation and discrimination, there are ethical transgressions in Jerusalem's archaeological arena that affect significantly larger segments of populations, with direct implications for the political reality of Israel's occupation of East Jerusalem. Several underground 
explorations-beginning relatively modestly with the Western Wall Tunnels immediately after 1967, and expanding significantly after the mid-1990s, including in the area below the Southeast Hill (City of David / Silwan) - are of relevance here. Both projects have been conducted under the auspices of the IAA, the former in collaboration with the Western Wall Heritage Foundation, the latter in collaboration with Elad. ${ }^{17}$ One of the shortcomings of these projects is that they rely heavily on excavation methods that undermine the stability of existing dwellings and public structures and thus necessitate the use of elaborate steel and concrete support systems. Steel pillars and scaffolding are problematic as they are excessively costly and compromise the appearance of the archaeological landscape.

Another shortcoming is that the excavations target select layers and features of the archaeological record, making it difficult or impossible to make an objective assessment of chronological and multicultural developments. Tunnel or shaft and gallery excavations were used commonly in excavations conducted before the British Mandate period. ${ }^{18}$ Warren, for instance, was trained in the art of military mining, which at the time was almost indistinguishable from standard archaeological methodology. ${ }^{19}$ Toward the end of the nineteenth century, the stratigraphic method of excavation was introduced in Egypt and Palestine by Flinders Petrie and gradually replaced tunnel excavations..$^{20}$ By the 1960 , this method was implemented in Jerusalem to the highest degree of rigor by Kathleen Kenyon, and it was established henceforth as the norm. Stratigraphic excavations expose accumulated layers of deposits of material culture and natural deposits layer by layer from top to bottom, enabling the archaeologists to define various phases of occupation. It prevents archaeologists from prioritizing specific features or periods and establishes a multilayered reconstruction of past cultures. The IAA's return to the use of tunnel and underground excavations is thus outdated and does not conform to current scientific methods.

Furthermore, the targeted exposure of remains that highlight the Jewish narrative, exemplified best in some of the excavations conducted on the Southeast Hill, thus compromises current archaeological practice, which aims to expose all the cultural aspects of one particular place over the course of many centuries. This method therefore represents an attempt to legitimize the Jewish presence in Silwan and obscure the ties of the neighborhood's current residents to the place. This approach has been aptly compared to early archaeological endeavors in Jerusalem, which were shaped by "[W] estern imperialist ambitions." ${ }^{21}$ Recovering the material remains of the biblical past, understood as the foundations of Western civilization, undermined the Islamic heritage as well as the Islamic presence in the city. In the nineteenth and early twentieth centuries, the biblical world was understood as a superior reality that was misunderstood and ignored by the oriental, backward-living locals. ${ }^{22}$ Notable parallels exist between this early colonial approach to the city's cultural heritage and the IAA's recent archaeological projects 
that have clear nationalistic aspirations, motivated by the desire to historically and archaeologically justify the Israeli occupation of East Jerusalem. According to current archaeological ethical standards, as advocated by professional organizations as well as by individual scholars publishing on related issues, the inclusion of local communities-in particular when excavations are conducted in residential areas-is strongly recommended. The local residents in Silwan are predominantly Palestinian-other than the growing settler community-and they should be involved in the excavation and interpretation process, partially in compensation for the disruption of their daily routines and living conditions, but, more importantly, to establish their connection to the area's cultural heritage, which should be recognized primarily as theirs. ${ }^{23}$ Several isolated attempts of community-based excavations conducted in other parts of the city could serve as a model for integrating Jerusalem Palestinian and Israeli residents in the process of exposing and understanding multicultural layers. Their impact, however, has been negligible. ${ }^{24}$

Another endeavor conducted under the auspices of Elad, which also fails to meet current archaeological ethical and professional standards, is the Temple Mount Sifting Project. After the construction of the Marwani Mosque inside "Solomon's Stables" between 1996 and 1999, the debris material was dumped at Abu Dis, on the western slope of the Kidron Valley, and at various other locations outside of the Old City. In 2005 it was moved to the Tzurim Valley National Park, and since then it has been systematically sifted (see figures 15 and 23). ${ }^{25}$ Since the finds do not come from a proper archaeological context and the debris has been moved at least twice since the renovations of the mosque, the procedure lacks scientific value. Chronological and typological observations do not contribute to our current knowledge of the city's material culture, and, most importantly, no stratigraphic or contextual conclusions can be drawn. ${ }^{26}$

The common denominator among these recent government-endorsed archaeological endeavors, other than the transgression of ethical and professional standards, is the manipulation of archaeological sites and finds and the resulting justification of Israel's occupation of East Jerusalem.

\section{ACQUISITION, COLLECTION, AND DISPLAY POLICIES}

The earliest documented interest in digging up artifacts in Jerusalem and other cities in the Holy Land and trading these objects locally and regionally is from the fourth century. After Empress Helena, the mother of Constantine, visited the Holy Land in 326, pilgrims began to flock to the region and acquired relics imbued with biblical meanings, including bones, shrouds, and the garments of saints and New Testament figures, thus contributing to the economy of the local religious establishments. ${ }^{27}$ In the eighteenth century, the continued demand for religious relics and icons was coupled with the newly emerging interest in acquiring 


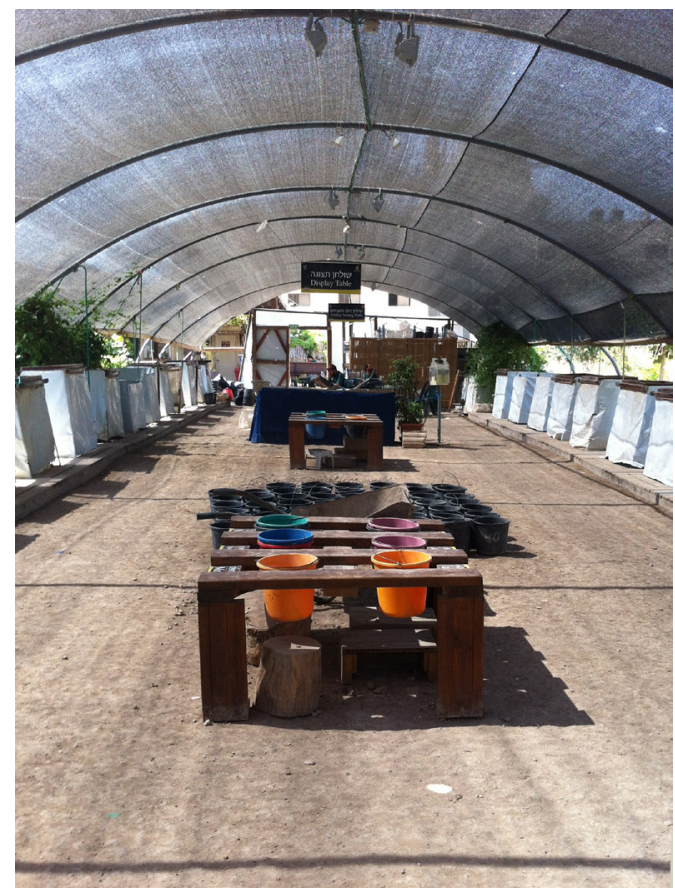

FIGURE 23. Temple Mount Sifting Project inside tent. Photo by Katharina Galor.

artifacts for scientific purposes. ${ }^{28}$ The Ottoman AL passed in 1874, which was revised and enhanced in 1884, was the first attempt to regulate the trade in local antiquities. ${ }^{29}$ Albeit largely unenforced, this law stipulated that all artifacts discovered in Ottoman territory were the property of the Imperial Museum in Constantinople. In this period, however, a complex smuggling network encompassing the region of Palestine and Syria was established, which has been linked to this Ottoman attempt to control European access to local cultural heritage. ${ }^{30}$ The 1920 Antiquities Ordinance, formulated by John Garstang, director of the Department of Antiquities in Mandate Palestine, and enacted by the high commissioner in 1929, introduced a much more professional and bureaucratic legal system of protecting cultural heritage, administered locally for the first time. ${ }^{31}$ The department issued licenses for the trade in antiquities, enabling dealers to officially engage in the business of buying and selling antiquities for the purpose of trade.

To this day, the 1929 Antiquities Ordinance still forms the basis for all domestic legislation concerning protection of cultural property in Israel and Palestine..$^{32}$ An official Israeli Antiquities Law was not enacted until 1978. Though adequate regarding its regulation of excavation and the requirement of full scientific publication, the legal precepts of the antiquities trade are, in many ways, regressive, in particular in comparison with other Mediterranean countries rich in archaeological 
remains, such as Italy, Greece, Turkey, and Egypt. According to the Israeli Antiquities Law, it is legal to buy and sell artifacts from pre-1978 collections and inventories. Numerous loopholes in this law, however, enable a continuous supply of illegally looted artifacts, which are sold by legally sanctioned dealers (both Israeli and Palestinians), almost all of whom are based in Jerusalem. ${ }^{33}$ The laundering chain is known to begin with the overseers and middlemen-Bedouin, Israelis, and Palestinians-who often finance the looting and then transfer the artifacts to legally sanctioned dealers. In Jerusalem, mostly in the Old City and East Jerusalem, but also in West Jerusalem, licensed IAA dealers are able to sell the material by using register numbers of similar, previously sold inventoried items, thus turning the objects into legally purchasable goods (see figure 24). The buyers are mostly tourists, some high-end collectors, educational institutions, and museums. ${ }^{34}$ Opinions regarding the legal trade and its impact on looting are divided between those who believe that legalized trade increases the market demand, which leads to more looting, and those who believe that if the selling of antiquities is banned, the market will go underground, as it has done in many other archaeologically rich countries. ${ }^{35}$ Proponents of a legal market have recently suggested to sell finds from the IAA storage facilities. Though it would temporarily provide extra income, the storage facilities would be depleted in less than a year and, according to some, rather than prevent the looting of sites and subsequent illegal sales, it would stimulate the market even further. ${ }^{36}$

The scientific and ethical concerns regarding the marketing of unprovenanced artifacts stem from the belief that removing an archaeological object from its find spot without professional supervision results in the irretrievable loss of context documentation and knowledge-and thus the displacement and destruction of local cultural heritage. ${ }^{37}$ As it is widely acknowledged that market demand fuels the incentive for looting, every individual and institution directly or indirectly involved in the trade of artifacts has a share in the ethical violation. Though not everybody involved in the chain-the looters, the dealers, the buyers, and the appraisers, who are often museum professionals or academic archaeologists-has equal responsibility in the legal transgression, all steps contribute in one way or the other to the trading, and thus the looting, of ancient artifacts. ${ }^{38}$ From an archaeologically ethical point of view, no amount of money obtained from the sale of an unprovenanced artifact can justify the irretrievable loss of cultural and historical knowledge.

Though it is commonly agreed upon that economic incentive drives most of the pillaging of archaeological sites, largely located in the West Bank, there are also other reasons. Looting is a leisure activity for some, undertaken in the evenings and on weekends, and for others, looting is a traditional activity, based on experience the looters gained as laborers on archeological excavations. ${ }^{39}$ Looting, however, can also be understood as a form of political resistance to the Israeli 


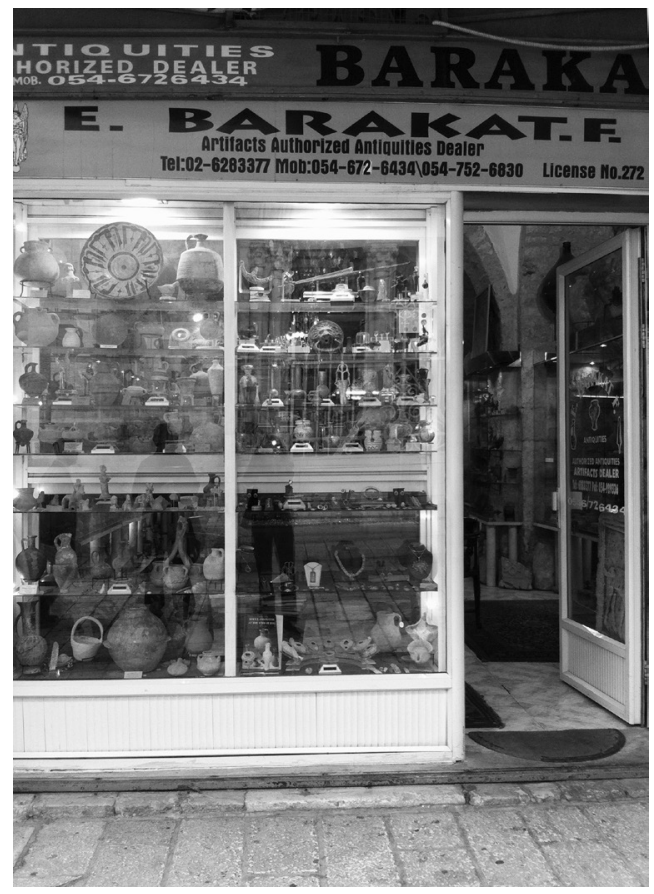

FIGURE 24. One of the many licensed antiquities dealers in Jerusalem's Christian Quarter. Photo by Katharina Galor.

occupation and subjugation of the Palestinian people. Other than realizing that there is a higher gain to be made from artifacts with a Jewish or Israeli connection, Palestinians often believe that by pillaging archaeological sites that are thought to bolster a Jewish claim to the land, this association can be erased. ${ }^{\circ 0}$ The looters perceive the cultural heritage of the artifacts as Israeli rather than Palestinian, which is a result of the prevailing public image projected by both foreign and local archaeologists, Israeli governmental institutions, and the media. ${ }^{41}$ In 1985 , in response to the growing public debate on looted antiquities, the IAA established the Theft Prevention Unit with the goal of limiting the robbery of archaeological sites and supervising the sale of antiquities. ${ }^{42}$ The effectiveness of policing this underground activity is questionable, however, as the risk of being caught and penalized is relatively minor in comparison to numerous other criminal acts, and the potential financial gains are higher. ${ }^{43}$

A market survey indicates that most objects traded are associated with the Judeo-Christian heritage. Particularly popular among tourists, the primary customers in Jerusalem's antiquities shops, are Herodian oil lamps and Bar Kokhba coins. ${ }^{44}$ Only in recent years has there been interest in objects related to the region's Islamic heritage; this market, however, is still underdeveloped. ${ }^{45}$ 
The vast interest in Judeo-Christian artifacts also determines the nature of the growing market in fakes and forgeries. Numerous coins, oil lamps, and glass and pottery vessels are sold as authentic ancient artifacts-both by Jerusalem dealers and in shops around the world, as well as online. In addition, there have been several sensational artifacts said to be from the First and Second Temple periods that have received worldwide media and scholarly attention partially as a result of their potential to document biblical narratives and to some extent because their authenticity is in doubt. There is, for instance, an ivory pomegranate originally thought to have adorned the High Priest's scepter used in Solomon's Temple. ${ }^{46}$ Next, the Jehoash inscription featured on a sandstone tablet describing repairs made to the Temple was previously perceived as roughly contemporary with the ivory pomegranate. ${ }^{47}$ Finally, there is the notorious James ossuary. It has an Aramaic inscription that says "James, son of Joseph, brother of Jesus," and it reportedly held the bones of the brother of Jesus; it was considered the earliest known archaeological mention of Jesus..$^{8}$ Most archaeologists and scientists have ultimately agreed that these objects are modern forgeries - the artifacts themselves are indeed ancient, but the inscriptions on them were added recently. The unprovenanced nature of these artifacts has remained largely ignored, both in the massive media attention and in the related scholarly discourse. ${ }^{49}$ In other words, there is very little awareness, even among archaeologists, that evaluating and authenticating ancient artifacts without provenance contributes - even if only minimally_to Jerusalem's flourishing antiquities market, the thriving looting activity, and the fakes and forgery industry.

The museum world has a similar impact on the public perception of the value of antiquities-monetary and otherwise. Various ethical boundaries have been crossed in several leading Jerusalem museum collections. These shortcomings, however, tend to be overshadowed by the high artistic quality of the finds exhibited, the popularity of the chosen themes, and the overall museological approach.

The oldest known publication concerning museum ethics dates from $1898 . .^{\circ}$ Other than the International Council of Museums (ICOM) code of ethics, a number of national codes were adopted in the 1970s, among these an Israeli one in 1979, as well as several codes for individual museums. Along with the codification of museum ethics, increased criticism of the collection policies and ethical standards of world-class museums - among others the Louvre, the Pergamon Museum, and the British Museum-has been voiced in the media and scholarly literature. Following the scandals of looted artifacts and their repatriation over the last decade, involving several renowned museums-including the J. Paul Getty Museum, the Metropolitan Museum of Art, and the Museum of Fine Arts in Boston-conventions and rules regarding the acquisition and display of looted or unprovenanced artifacts in museums have changed quite dramatically. ${ }^{51}$

In some aspects, the ethical standards of most Jerusalem museum collections do not fall behind international museum principles, which are still struggling to 
adjust to the new acquisition and collecting philosophies. In most ways, however, Jerusalem presents a unique case, because internal politics and regional conflicts impact the professional standards. As opposed to most European and American collections, which are criticized for holding artifacts looted in the context of nineteenth- and early twentieth-century imperialist travels and conquests, Israeli museums mostly display recently acquired or excavated artifacts, a large majority of which were found after 1948. The percentage of unprovenanced finds in Jerusalem collections is not particularly high in comparison to other international museum holdings. These include the collections of archaeology professors Nahman Avigad and Yigal Yadin, which were absorbed by the Museum of Jewish Antiquities at the Hebrew University, as well as Teddy Kollek's and Moshe Dayan's collections, which were sold or donated to the Israel Museum..$^{22}$ Unique, however, is the high prestige, academic visibility, and political stature generally associated with these collectors within Israeli society. The Israel Museum's reception celebrating the acquisition of the Dayan collection in 1986 led to an organized protest by local archaeologists, but ultimately, it did not have an effect on the decision to absorb the looted artifacts into the permanent collection. ${ }^{53}$ Even more at odds with ethical museum standards are the Bible Lands Museum holdings, which consist almost entirely of Eli Borowski's private collection. This collection is made up of looted artifacts acquired through a well-documented process of laundering, in which artifacts pass from the hands of professional grave robbers to middlemen and then to antiquities dealers and auction houses. Borowski's implication in this illegal network was recently established in a document discovered by the Comando Carabinieri Tutela Patrimonio Culturale, a special unit of the Italian police in charge of the protection of cultural heritage. ${ }^{54}$

Politically sensitive, and thus equally questionable from an ethical viewpoint, is the appropriation and display of artifacts that come from the occupied Palestinian territories. The Rockefeller Museum, despite official agreements reached after the 1967 takeover by Israeli authorities, followed the directives of the IAA and loaned to other museums some of the artifacts in its original collection, which were meant to remain on the grounds..$^{55}$ This fact has remained largely unnoticed by the general public. The same ethical reservations concern other Israeli museums that display artifacts found in excavations carried out in occupied East Jerusalem.

Similar transgressions occurred in the recent Herod exhibit at the Israel Museum. Media figures, activists, and scholars criticized the display of finds uncovered in the West Bank and removed by Israel without the approval of the Palestinian Department of Antiquities. ${ }^{56}$ Despite the fact that these artifacts were professionally excavated and documented, they were illegally appropriated from occupied territory, implying the unethical removal and appropriation of cultural heritage.

Though ethical standards pertaining to museum collections have changed substantially over the past four decades, both internationally and in Israel, the political 
situation in Jerusalem will almost always compromise professional conscientiousness and progress. It is true that today university professors can no longer collect, as Avigad and Yadin did in the past, and today politicians cannot rely on the public endorsing private collections of looted antiquities, as Teddy Kollek or Moshe Dayan did in the 1960s and 1970s. Trading, however, is still legal, displaying looted and unprovenanced artifacts is the accepted norm, and transferring objects from occupied Palestinian territories, including East Jerusalem, and exhibiting them in the city's national museum is a celebrated achievement.

Along with admiring Jerusalem's exposed ruins and viewing artifacts in public museums, collectors, tourists, and pilgrims can legally purchase antiquities and take them home. The focus on Judeo-Christian artifacts that determines the nature of Jerusalem's numerous markets and collections indicates the prevailing and persistent interest in biblical artifacts, and to some extent the overlapping taste and ideological confluence of Zionist and Evangelical Christian consumer groups. The proliferation and accessibility of this relatively narrow chronological spectrum of antiquities in recent years exemplifies how commerce, religious beliefs, ideological perceptions, and political agendas are intertwined and feed each other.

\section{THE EXCAVATION AND DESECRATION OF TOMBS}

Our knowledge about early human activity is derived to a large extent from the material remains of burials. The exploration of tombs has always played an important role in the study of ancient civilizations, providing valuable insights on funerary customs and the belief in an afterlife, as well as on cultural developments, changes, and affiliations more generally. Furthermore, anthropological studies of burials can offer much helpful information on gender, ethnicity, DNA, genetic disorders, diseases, and nutrition.

It may come as a surprise that scholars as well as archaeological and anthropological societies have only recently initiated formal codes of ethics addressing the complexity of digging up and studying the mortal remains of the dead. The Vermillion Accord on Human Remains, adopted in 1989 at the World Archaeological Congress, advocates for respect to be paid to human remains "irrespective of origin, race, religion, nationality, custom and tradition." It further stipulates that the value of scientific research of skeletal, mummified, and other human remains should be demonstrated and should not be taken for granted.

In Jerusalem, and in Israel more broadly, major controversies regarding the excavation and study of ancient burials have gained wide public attention. Heated debates and actual conflicts have erupted around perceived cultural, ethnic, and religious links between past and present communities, particularly sensitive in the context of Jewish and Muslim tombs and cemeteries. Surprisingly, however, the AAI code of ethics has not addressed the issue of excavating burials, and formal 
restrictive policies regarding the excavation and scientific study of ancient burials were not established until 1994.

The very first excavation conducted in Jerusalem, in 1850-51, was devoted to the exploration of an ancient burial complex. De Saulcy had obtained an official firman from the Ottoman authorities to explore the so-called Tomb of the Kings. This endeavor caused turmoil among the local Jewish community, who complained that the graves of their ancestors had been desecrated. ${ }^{57}$ Despite the anger, which forced de Saulcy's escape from the region, the excavation of ancient tombs in Jerusalem proceeded in a relatively undisrupted manner for nearly a century.

Since 1967 , as a result of the dramatic proliferation of urban development projects in and around Jerusalem, a number of particularly controversial incidents have led to heated debates among archaeologists, other scholars, and the general public, some of which were brought before the Israeli Supreme Court. Several cases have caught the attention of local and international media.

Among the most contentious cases in Jerusalem are excavation projects that were interrupted by protests led by Atra Kadisha (Aramaic for holy place or holy site), an ultra-Orthodox fringe group invested in protecting ancient Jewish tombs. ${ }^{58}$ Their goal is to prevent the desecration of Jewish graves, and in most cases, their opposition to archaeological excavations is linked to major development projects. In their view, opening and penetrating ancient tombs represents a violation of Jewish law as it pertains to the respect to be paid to the dead. ${ }^{59}$ Though exclusively concerned with Jewish burials, their resistance also affects burials associated with other cultures and religions. ${ }^{60}$

Atra Kadisha was first established between 1957 and 1959, as a response to excavations carried out at Beit Shearim, a Jewish town and cemetery from the Roman and Byzantine periods in southwestern Galilee. Their interference with archaeological excavations in Jerusalem, often entailing violent and destructive behavior, only started to have significant professional and legal implications in the 1990s, following protests and demonstrations in French Hill and Mamilla near Jaffa Gate. ${ }^{61}$ Unlike the salvage excavation carried out in French Hill, which exposed primarily Jewish tombs from the Second Temple period, the excavations conducted in Mamilla exposed a Christian mass grave from the time of the Persian capture of Jerusalem in 614 C.E. ${ }^{62}$

These and other cases were brought before the Israeli Supreme Court, leading to a directive issued by attorney general Michael Ben-Yair on July 22, 1994, that stated that archaeologists must show proper "respect ... in handling the bones of corpses," and that human bones must "be forwarded, after their examination, to the Ministry for Religious Affairs for burial." ${ }^{3}$ Protests led by Atra Kadisha, however, have continued regardless of the new regulations and despite the fact that the IAA has limited the exposure of tombs and cemeteries-not only Jewish, but also pagan, Christian, Muslim, and even prehistoric ones to a minimum. In 1998, in an 
attempt to calm the situation, the Israeli government appointed five Orthodox rabbis to the Archaeological Council, a body that consists of thirty-eight archaeologists and other experts who advise the IAA on granting excavation permits. Unlike Atra Kadisha, who argue that any disturbing of burials goes against Jewish law, Orthodox rabbis have mostly agreed that bones can be removed so that excavations can proceed. ${ }^{64}$ Nevertheless, even the Ministry of Religious Affairs representing the Orthodox community insists that bones must be reburied without being studied by anthropologists, the procedure that was followed in Israel before the clashes in the 1990s. The more recent structure introduced in 1998 has been conditioned by Atra Kadisha's continued opposition to the excavation of burials, who not only disregard the directives of the Supreme Court but also the authority of the Ministry for Religious Affairs. Despite the fact that not all Orthodox and ultraOrthodox individuals and communities agree with Atra Kadisha's position on the excavation of burials, their body has an indirect influence on religious groups and parties active within the government and the Knesset. ${ }^{65}$

Another highly controversial case is the late Ottoman (and more recent) construction on top of Jerusalem's largest Muslim cemetery in Mamilla, located to the west of the Old City and within the boundaries of the Historic Basin. ${ }^{66}$ The burial ground is centered around a shallow rectangular water reservoir, known as the Mamilla Pool. According to popular tradition, the cemetery holds the remains of several of the Prophet Muhammad's companions. Numerous religious, political, and military leaders, eminent scholars, and various other Jerusalem notables are known to have been buried there over the last millennium. ${ }^{67}$ The burial grounds were once densely covered with tombstones and memorials, most of which are now gone. Among the few remaining are several Mamluk and Ottoman burial plaques and monuments, and most notable among them are the thirteenthcentury mausoleum al-Qubba al-Kubakiya for 'Ala' al-Din Aidughdi al-Kubaki (see figure 25), the governor of Safed in the Mamluk Sultanate and the sixteenthcentury tomb of Sheikh Dajani. ${ }^{68}$

The boundaries of the cemetery were established during Ottoman rule in the 186 os. $^{69}$ The Mamilla Cemetery was declared an antiquities site in 1944 by the British Mandatory authorities, a status that was twice reconfirmed under Israeli rule, first in 1964 and then again by the IAA in 2002. ${ }^{70}$ Recent excavations conducted in sporadic areas have established four archaeological strata and hundreds of burials ranging in date from the eleventh century to the beginning of the twentieth century. ${ }^{71}$ Ever since the expansion of the city beyond the Ottoman walls in the 1860 s, modern roads and buildings started to slowly encroach upon the cemetery. It was not until the 1950s, however, that significant areas of the burial grounds were appropriated for the construction of residential and commercial or other public spaces and buildings. In 1986 this led to a petition by Palestinians to UNESCO. The most controversial case has been the recent construction of the so-called Center 


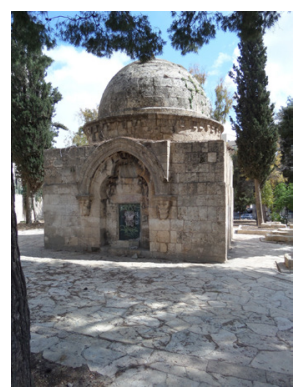

FIGURE 25. Al-Qubba al-Kubakiya. Photo by Katharina Galor.

for Human Dignity-Museum of Tolerance, initiated in 2004. The first Museum of Tolerance was established in Los Angeles, California, in 1993, designed as the educational arm of the human rights organization the Simon Wiesenthal Center. Like its American counterpart, the Jerusalem museum was also to examine racism and prejudice around the globe, with a focus on the Holocaust. Following the standard procedure for new development, salvage excavations were carried out that established the density of human burials. The excavation and building activity has generated heated debates and resulted in numerous lawsuits as well as public protests in both Israel and around the world. Several petitions were filed urging Israel to halt the construction of the Museum of Tolerance and to honor the "cultural and archaeological importance of the cemetery to the history of the Holy City of Jerusalem." ${ }^{22}$ In 2011, the Supreme Court granted permission to go forward with the construction, based on a report submitted by the IAA, though that report has been challenged for its accuracy, including by the archaeologist originally assigned to direct the excavation. ${ }^{73}$ The project disinterred significant numbers of graves, estimated at least in the hundreds. Additional construction on top of the Muslim Cemetery and adjacent to the site of the Museum of Tolerance, consisting of 192 housing units, a 480-room hotel, commercial spaces, and parking, was approved in July of 2015 by the Jerusalem Planning and Building Committee. ${ }^{74}$

This gradual encroachment upon the Mamilla Cemetery and the disrespect paid toward the human remains buried in this area is particularly striking in comparison with another historic burial ground in Jerusalem. The Jewish cemetery on the Mount of Olives, which, according to tradition, goes back to the time of King David and includes tombs that date back hundreds of years, has not fallen victim to modern development.

\section{BONES AND BURIALS OF CONTENTION}

In many ways, the controversies and confrontations surrounding the excavation and study of human remains in Jerusalem reflect the tensions between the Jewish 
secular and religious sectors of Israeli society, as well as the conflict between Jewish and Muslim communities, Israeli governmental establishments and Palestinian national entities. Opposition to the excavation and desecration of ancient tombs and cemeteries mostly stems from the desire to protect religious communitiestheir beliefs and practices-rather than the individual. In contrast to the actual act of excavating tombs, however, very few ethical concerns have been voiced regarding the use of burial goods as cultural, educational, or commercial commodities, once they have left the ground.

Two displays at the Israel Museum reflect the complexity and evolving perception of archaeological ethics as they affect changing professional standards, past and current acquisition and display policies, and finally the exploration of ancient burials. The ethical concerns in these and most other cases dealing with funerary remains are intricately linked with the always sensitive and often explosive social and political climate in Jerusalem.

Several anthropoid Canaanite coffins from Deir al-Balah, which greet visitors as they enter the newly renovated archaeology wing at the Israel Museum (see figure 26), are widely known to have been looted by Dayan at a time when the Gaza Strip was under Israeli military administration..$^{75}$ They were dug up and transported to Dayan's home sometime in the 1970s, using military equipment, and were then sold to the museum in 1982 by his widow. ${ }^{76}$ Thus, both the process in which the artifacts were uncovered, as well as their acquisition and display are highly questionable with regard to professional standards, as officially professed by Israeli archaeologists and museum professionals.

Perhaps equally blatant in its politically and ethically compromised curatorial choice was the focus of the Israel Museum's Herod exhibit on the latter's alleged sarcophagus and funerary monument. ${ }^{77}$ Though the artifacts on display were excavated by applying the most up-to-date scientific methods, the show defied international law-as well The Hague's convention-by incorporating finds from occupied territory. ${ }^{78}$ Herod, this man who was both feared and hated by his Jewish contemporaries, has risen to become Israel's most illustrious king. It appears that the legacy he has left behind is more palpable than that of Kings Saul, David, and Solomon, whose only traces consist of the biblical narrative. Hundreds of thousands of enthusiastic visitors, mostly Jewish, arrived to circumambulate his tomb in the galleries of the Israel Museum, recalling the motion of millions of Christian pilgrims paying homage to the tomb of Christ at the Holy Sepulchre. Herod would most likely have taken great satisfaction in knowing that his tomb was given so much honor and attention, and by no one less than the Jewish people. This, in the end, was his goal when he planned his funerary monument to be set up at Herodium. The question, however, is whether displacing and appropriating funerary monuments by completely altering their original functions impinges on the deceased's ethical rights, perhaps no less severely than the exhumation of one's bones. 


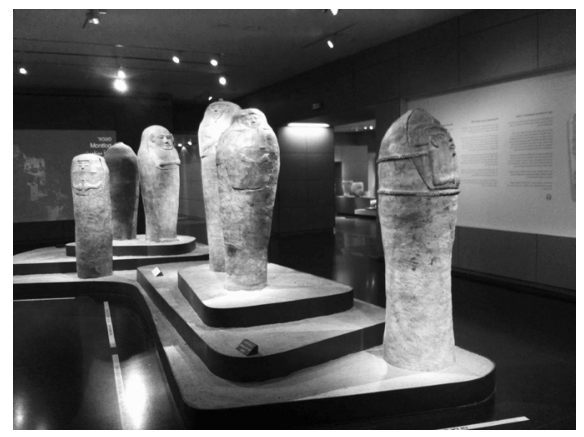

FIGURE 26. Canaanite coffins from Deir al-Balah at entrance of Israel Museum's archaeological wing. Photo by Katharina Galor.

The transgressions of ethical norms in the professional, educational, and commercial realms of archaeological practice in post-1967 Jerusalem, with significantly higher impact after the mid-199os, do not appear to have significantly influenced the public image of archaeology. The general perception, among most Israelis and tourists, has been and continuous to be that engaging in archaeology is an overall virtuous endeavor.

My hope, though, is that by exposing some of the existing and persistent misconceptions on archaeological practice and its role in the public sphere, and by creating awareness of what is professionally viable and ethically defendable, we can have a better understanding of how issues of cultural heritage play themselves out in the following case studies. How has archaeological fieldwork and research contributed to our knowledge of some of Jerusalem's most venerated sites and monuments? Who and what has impacted the specific explorers and explorations involved? And how did these together shape public information and opinion? Can we untangle the elements that contribute to the confluence of science, religion, and ideology? 